cial preoccupations of the Eugenics Society, particularly in relation to the nature of and possible remedies for mental disorder and mental subnormality. One would hardly trade this volume for that of Kevles; but neither should we discount the value of Mazumdar's own contributions to a theme still pregnant for us, the generation of the genome.

W. F. Bynum is at the Wellcome Institute for the History of Medicine, 183 Euston Road, London NW1 2BN, UK.

- In The Hour of Eugenics: Race, Gender, and Nation in Latin America, Nancy Leys Stepan compares the eugenics movements in Mexico, Brazil and Argentina with those of Britain, the United States and Germany. Published by Cornell University Press, price $\$ 31.50$.

\section{Mere platonic invention?}

Colin Renfrew

The Flood from Heaven: Deciphering the Atlantis Legend. By Eberhard Zangger. Sidgwick and Jackson: 1992. Pp. 256. £17.50, \$22. (To be published in the United States by William Morrow on 20 August.)

PLATO has a lot to answer for. In setting out the story of the vanished civilization of Atlantis (for which his writings are the only source), he has been the root cause of a great deal of unprofitable speculation. Some of the speculation has been fanciful beyond the bounds of reason, whereas other versions, such as that presented in this book, are honest attempts to make some sense of what he wrote. The story as reported by Plato (allegedly told by priests in Egypt to the Greek sage Solon some centuries earlier) places the doomed civilization in the Atlantic Ocean, and its demise some 9,000 years before Plato. In the light of current understanding, neither of these claims can be correct, and all modern authorities who take the story seriously are obliged to alter both the location and the date. That is where the trouble begins.

In recent years, a favourite contender has been the volcanic island of Thera in the Cyclades. For here, at least, was a worthy cataclysm, resulting in the destruction and burial of the Bronze Age city somewhere around the seventeenth century $\mathrm{BC}$ at what is now Akrotiri. Several authors have claimed that Thera fits the bill - as it may well do if place, time and other details are conveniently varied. For a while, the entire civilization of Minoan Crete was seen as a candidate, the collapse of the Minoan

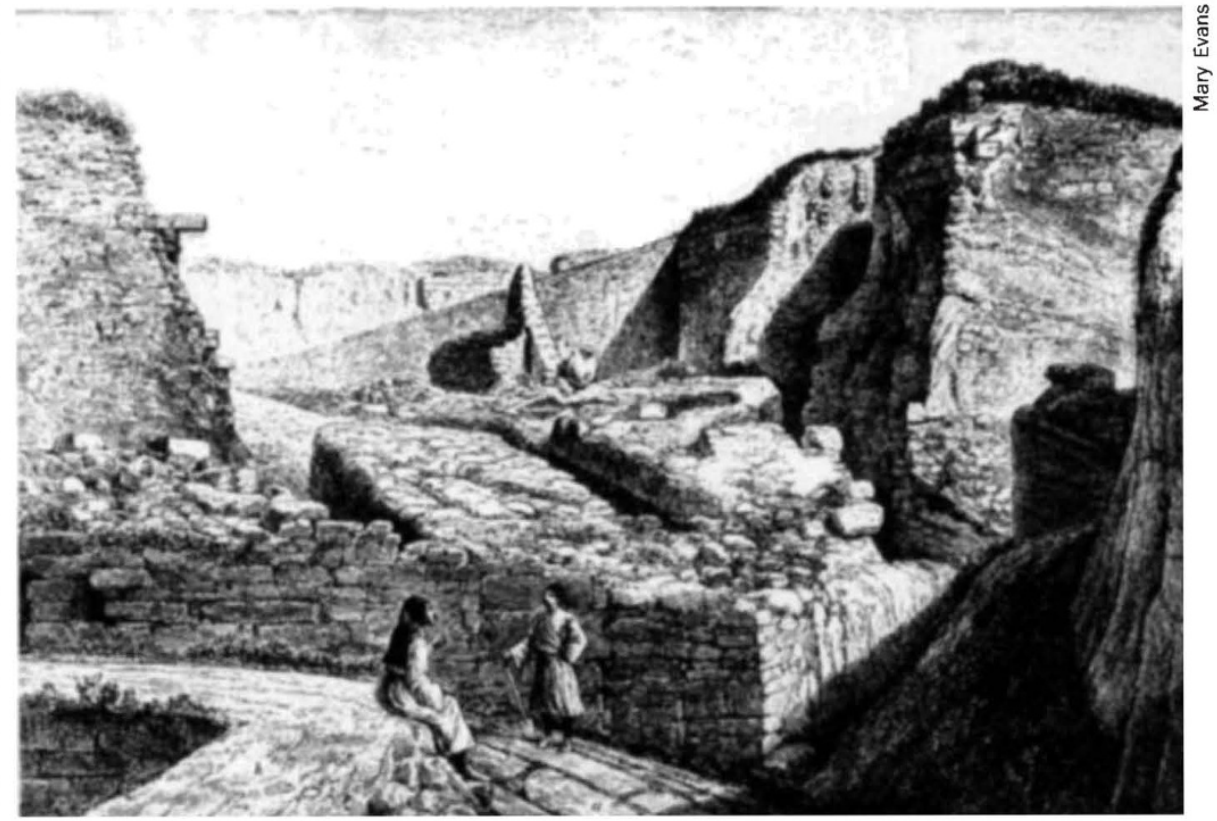

Digging for Atlantis? Excavation of Hissarlik, claimed as Troy, by H. Schliemann in 1873.

palaces being plausibly attributed to the Thera eruption. But that suggestion no longer finds favour, and another Atlantis theory vanishes beneath the waters.

Eberhard Zangger has an alternative and ingenious candidate: for him Atlantis equals Troy. As a geomorphologist, he is well placed to argue that the ancient topography of the site of Hissarlik, excavated and claimed as Troy by Heinrich Schliemann, has changed significantly since the time of the Trojan War, some 3,000 years ago. His suggestion has one notable strong point, to my mind. For in Plato's Atlantis story it is stated that the forces of Solon's homeland (Athens) had defeated those of Atlantis before the cataclysm that brought about its disappearance. And of course the most important feature of the Greek legends relating to Troy was the Trojan War itself, and the capture of the city by the Hellenic forces.

Inevitably, however, Zangger has to modify the Platonic data on time and place. Moreover, he accepts both the real existence of the Trojan War (a point disputed by many scholars, most notably the late Sir Moses Finley) and its identification with the site of Schliemann's excavations. These are inevitable difficulties. They are compounded by the special arguments needed to make the Trojan landscape conform to the Platonic description of Atlantis, and by the absence of any satisfactory natural calamity to bring about the disappearance of Troy. For, if correctly identified, the site was still there in classical Greek times, when a temple was built, and remained to await the spade of Schliemann.

Zangger's own recent work has been at the Mycenaean citadel of Tiryns in the
Argolid (southern Greece). There he has found good evidence of a large flood, probably earthquake-induced, that covered much of the lower city with mud around $1200 \mathrm{BC}$. But although much is made of this circumstance in his book, he does not imply a larger, pan-Aegean catastrophe that might have engulfed Troy at that time (and, as noted above, the site of Hissarlik itself remains obstinately un-engulfed, although the topography, and especially the coastline, have certainly changed since then).

This book is well written. The relevant texts from Plato are printed in full and carefully discussed. The case that Zangger is making is not overstated. In one sense it is perhaps understated, because the relevance of his own observations at Tiryns to the history of Troy is not spelt out very clearly, and indeed remains to me obscure. For the sceptic, therefore, for whom even the historical reality of Troy and the identification of Hissarlik with it are problematic, the central thesis that Atlantis was Troy is unpersuasive. As Atlantis books go, this is a perfectly sane and well-argued one, written by a competent scholar. But Aristotle was one of the first to suggest the view, pithily expressed by Francis Cornford in 1937 (and quoted by Zangger), that "serious scholars now agree that Atlantis probably owed its existence entirely to Plato's imagination". Until Egyptologists unearth the hieroglyphic inscriptions upon which Solon's Egyptian informants supposedly relied, I shall incline towards Aristotle and Cornford rather than towards Plato and Zangger.

Colin Renfrew is in the Department of Archaeology, University of Cambridge, Downing Street, Cambridge CB2 3DZ, UK. 